\title{
TUNING: PERSONALIZACIÓN DE OBJETOS O CREACIÓN DE OBJETOS ${ }^{1}$
}

\section{Tunning: Customize objetc or creating objets}

\author{
DANiEl ZaPATERO \\ Universidad Complutense de Madrid (UCM) \\ dzapatero@art.ucm.es \\ Violeta Agudín \\ Licenciada en Bellas Artes (UCM) \\ violet_art83@hotmail.com
}

Recibido: 3 de junio de 2011

Aprobado: 8 de julio de 2011

\section{Resumen:}

Generar materiales de juego especialmente diseñados para uso hospitalario ha sido uno de los objetivos del Proyecto Curarte I+D. Los talleres "tunning" funcionaron como un taller de arte colaborativo en el que diseñadores, adolescentes hospitalizados y educadores participaron en el diseño de un prototipo de juguete para ellos mismos.

Palabras clave: Art workshops, adolescents hospitalized, toys design.

Zapatero , D. Agudín, V. 2011: Tuning: Personalización de objetos o creación de objetos. Arte, Individuo y Sociedad, Vol.23, Núme. Especial, 89-97.

\section{Abstract:}

One of the aims of curarte I+D proyect have been the developing of games and toys with specific desing in order to be use in hospital by children and adolescents. "Tunnig" workshop was an art workshop where designers, adolescents hospitalized and art educators participated in designing a prototipe of toy. Key words: Art workshops, adolescents hospitalized, designing toy

Sumario: 1. Introducción, 2. ¿Por qué diseñar un muñeco para adolescentes?, 3. Diseño del prototipo y variaciones, 4. Conclusiones. Referencias.

\footnotetext{
${ }^{1}$ Esta investigación ha sido financiada por el Ministerio de Ciencia e Innovación (EDU200805441-C02-00/EDU) 


\section{Introducción}

Durante los últimos cuatro años, el proyecto Curarte $\mathrm{I}+\mathrm{D}$ ha trabajado en el diseño de materiales de juego creativo especialmente adaptados para el contexto hospitalario. En este marco de acción, surgen los talleres y propuestas de "Tuning". "Tuning" es un proyecto cooperativo donde adolescentes hospitalizados, educadores, investigadores y diseñadores participan en el diseño y la creación de un prototipo de muñeco para ser tuneado.

\section{2. ¿Por qué diseñar un muñeco para adolescentes?}

¿Quién no se acuerda de los originales libros de texto del instituto, que se personalizaban con notas, dibujos propios o de los compañeros; o aquellas famosas carpetas, llenas de imágenes de futbolistas, cantantes, poesías, dedicatorias, que hablaban de gustos, aficiones, fanatismos desenfrenados; en definitiva: aquel maravilloso "tuneo" adolescente?

La palabra "Tuneo" (del inglés "Tuning") ha adquirido con el paso del tiempo en nuestra cultura, no sólo el valor de un hobbie en el cual se personalizan objetos cotidianos tales como coches, móviles, los fondos de pantalla del ordenador, la ropa, o la propia piel (tatuaje), sino que pasa a ser un "movimiento de acción" que identifica a la persona que transforma dicho objeto.

Los adolescentes contemporáneos "tunean" sus propios objetos, los personalizan y además los exhiben. Cuando personifican objetos, están trabajando plásticamente su identidad, y los talleres desarrollados y evaluados en está unidad (Pascale y Ávila, 2007) que trabajan la identidad desde propuestas plásticas como el tatuaje o el graffiti han funcionado muy bien.

Lo que se propone a través de los talleres "tuning" es que los adolescentes trabajen su propia personalidad a través de la proyección plástica. Teniendo claro que el "tuneo" puede ser una herramienta interesante para la creación entre los adolescentes, hay que generar los contenidos, metodologías de acción y por supuesto los materiales para que esta acción de tunear sea efectiva en la realidad del adolescente hospitalizado.

El punto de partida lo encontramos en los talleres "Playmobilízate" (Megías, 2008). En la Unidad de Psiquiatría de Adolescentes del Hospital Gregorio Marañón, se trabajó con el grupo de adolescentes para la realización de un autorretrato, interviniendo un clic de playmobil para reflexionar sobre la apariencia física y la construcción de la identidad. En la Unidad de Oncología del mismo hospital, el trabajo con los adolescentes se planteó desde otra perspectiva, dado que los efectos de la enfermedad y su tratamiento en la apariencia física de los pacientes hace que sea delicado tratar el autorretrato (Ullán et al., 2009). En lugar de realizar un autorretrato, las participantes modificaron el muñeco diseñando el pijama que les gustaría llevar, dado que el que les proporciona el hospital no es demasiado apropiado para su edad. El hecho de diseñar este pijama los invitaba a realizar un autorretrato sin proponérselo directamente. La realización de la actividad fue acompañada por una encuesta en la que describían cómo debía ser la ropa durante los días de hospitalización. 

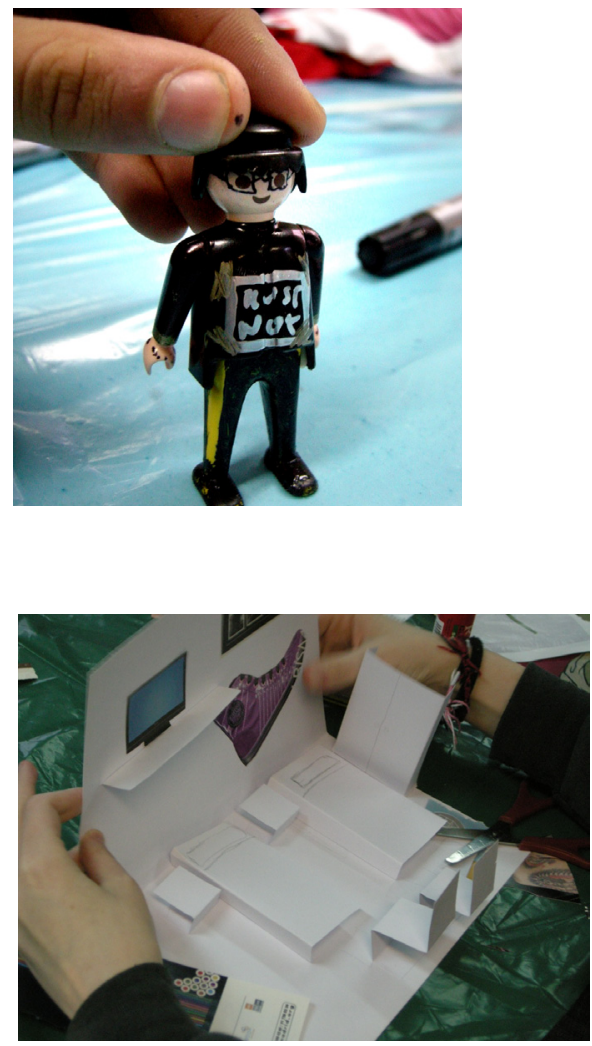
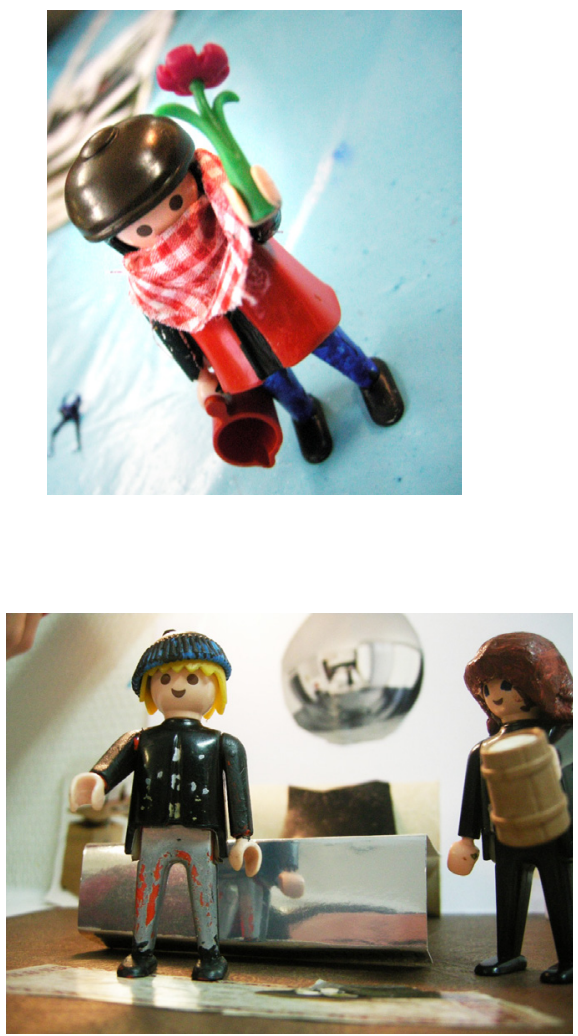

Fig. 1, Fig.2, Fig. 3, Fig. 4. Resultados de los talleres en la Unidad de Psiquiatría de Adolescentes del Hospital Gregorio Marañón. Foto: Clara Megías.
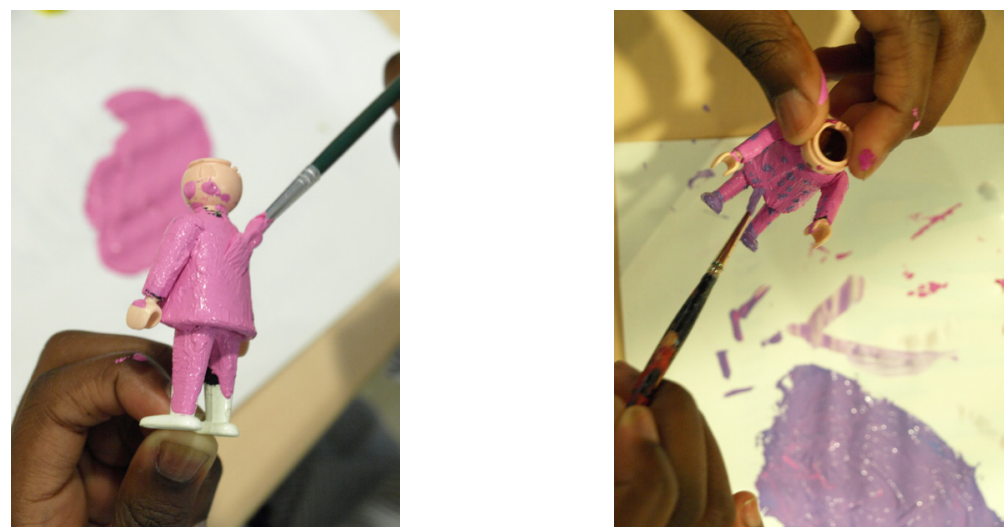

Fig. 5 y Fig. 6: Resultados de los talleres en la Unidad de Psiquiatría de Adolescentes del Hospital Gregorio Marañón. Foto: Clara Megías. 
Estos talleres suponen un primer acercamiento y plantean la necesidad de generar un material propio con el que poder trabajar. Generar un muñeco más limpio que permita incorporar cambios más fácilmente a los chicos que lo intervengan.

\section{Diseño del prototipo y variaciones}

Planteada la necesidad de generar un objeto propio, se decide incorporar al propio adolescente en el proceso de diseño del mismo. De tal modo que no solo se trata de tunear un objeto existente, sino trabajar en la creación del propio objeto, del propio soporte de la acción. Si ellos serán los usuarios, ellos podrán ser los diseñadores del muñeco que mejor se adapte a su criterio.

Para ello se realizan una serie de pruebas con material moldeable (pasta blanca) en la que los chicos intentan generar sus propias figuras, no con demasiado éxito.

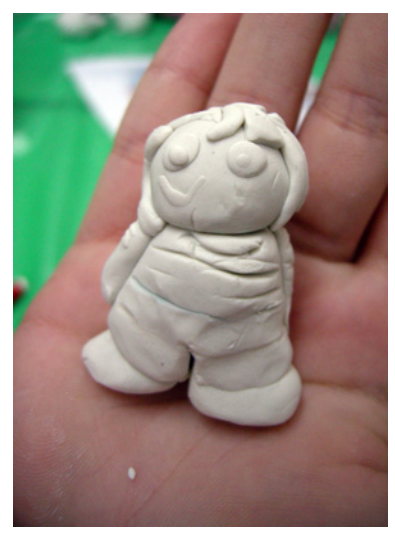

Fig. 7. Figura realizada por un adolescente con plasta blanca. Autora: Clara Megias.

Simultáneamente, los diseñadores e investigadores del proyecto CURARTE revisan los materiales y objetos que existen en el mercado para ser "tuneados", y surge un primer boceto para el muñeco que será generado en varios materiales.

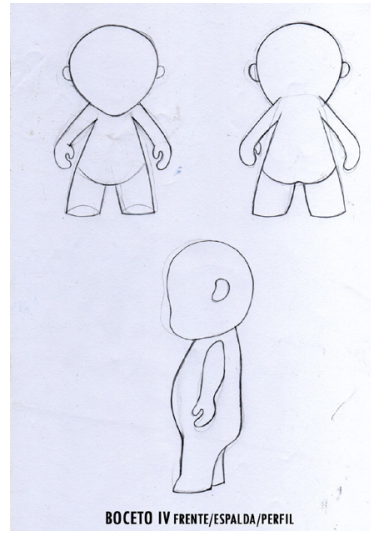

Fig. 8. Boceto.

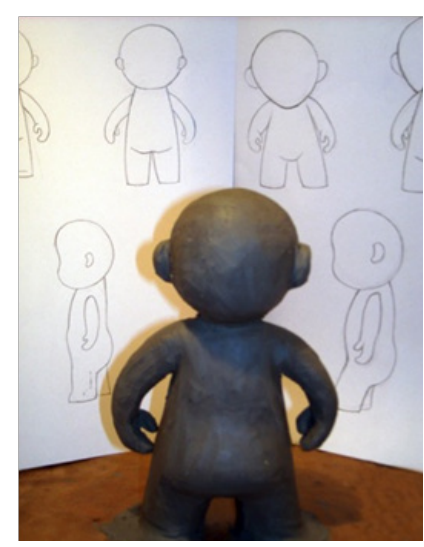

Fig. 9. Prototipo en Plastilina. 


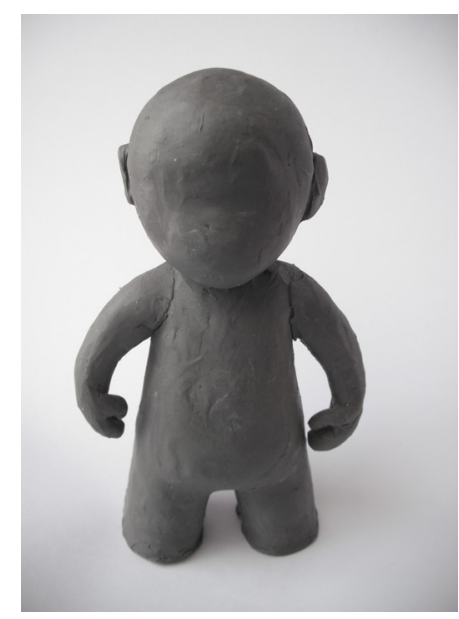

Fig. 10. Prototipo en 3D.

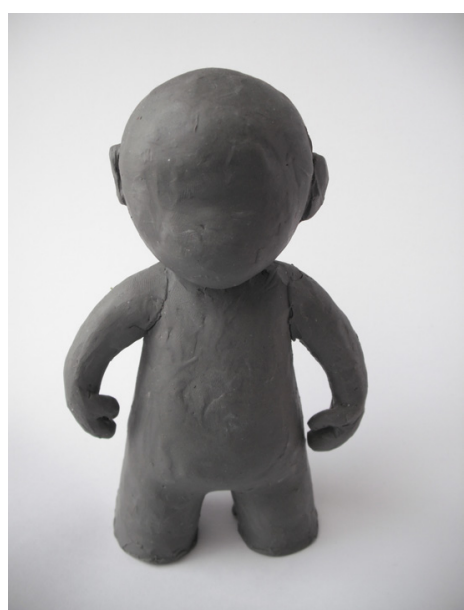

Fig. 11. Prototipo en resina.

A partir de los bocetos y de las imágenes de este primer prototipo se desarrolla un taller de dibujo muy interesante. En él los adolescentes de la Unidad de Psiquiatría trabajan sobre los modelos fotográficos, modificando mediante el dibujo aquellos elementos que consideren en el prototipo. De nuevo, de forma indirecta los chicos vuelven a trabajar la identidad a través de la línea y el dibujo.Con la información de estos dibujos se extrajeron ideas nuevas para el prototipo: fragmentarlo en partes intercambiables o que los pies y las manos deberían tener un mayor protagonismo.

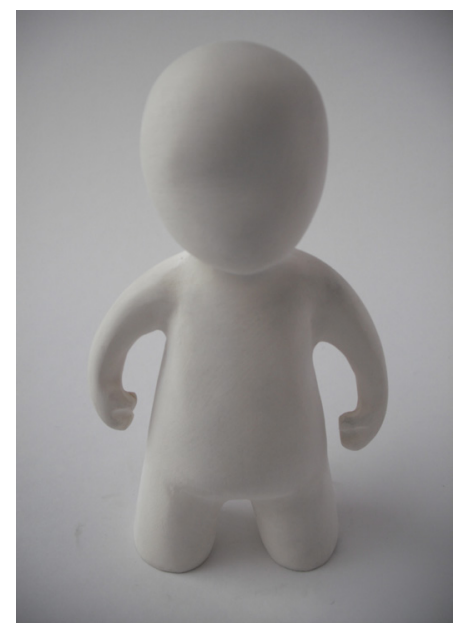

Fig. 12. Reproducción del prototipo en resina.
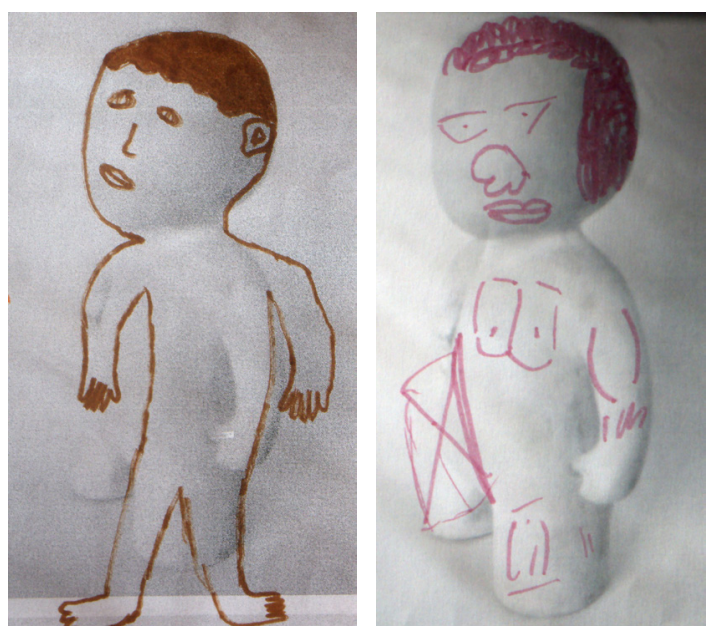

Fig. 13, 14. Dibujos sobre las fotocopias del prototipo. 

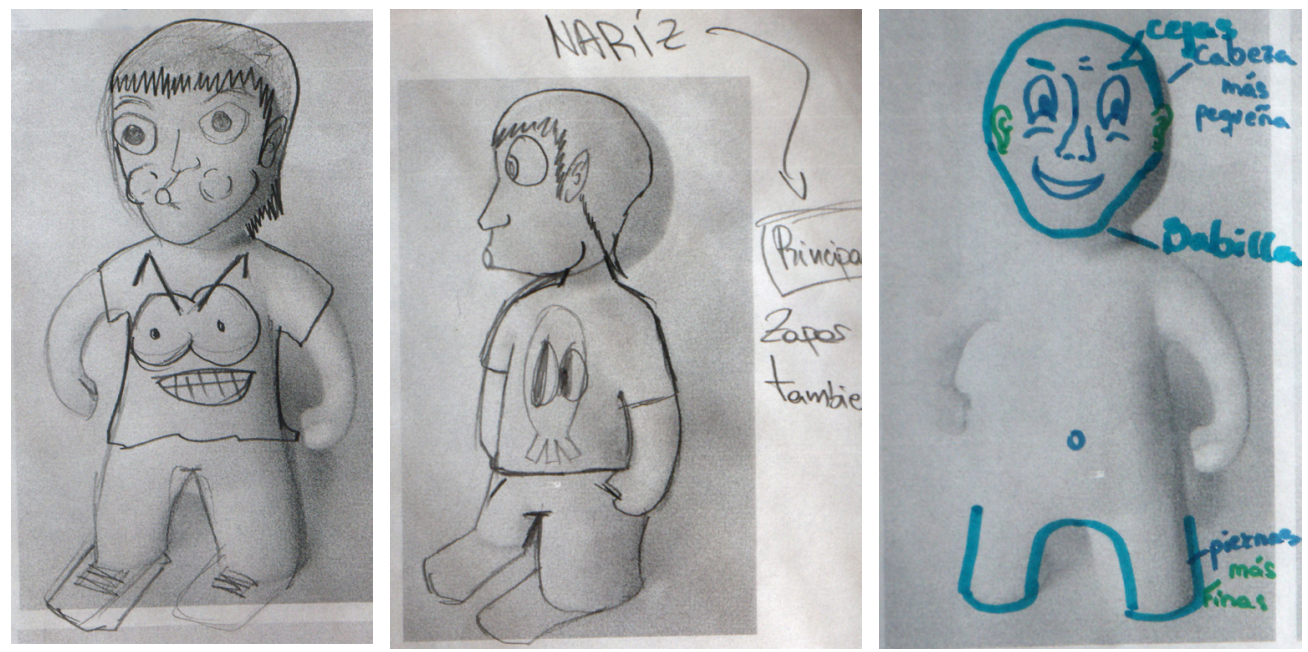

Fig. 15, 16, 17. Dibujos sobre las fotocopias del prototipo.

A partir de las adaptaciones que los pacientes han realizado el primer prototipo, comenzamos a diseñar un nuevo muñeco por piezas y no en bloque. Se diseñan cuatro cabezas, cuatro torsos, cuatro pares de brazos, y seis pares de piernas.

Con ello intentamos conseguir que el paciente pueda interactuar con multitud de piezas a la hora de diseñar su muñeco; que tenga la posibilidad de trabajar con diferentes partes que, dispuestas en distintos modos, creen diversidad de posturas y formas en el mismo. Y para que estos objetivos sean posibles, es necesario que el material de las diferentes piezas sea ligero, adaptable y flexible.

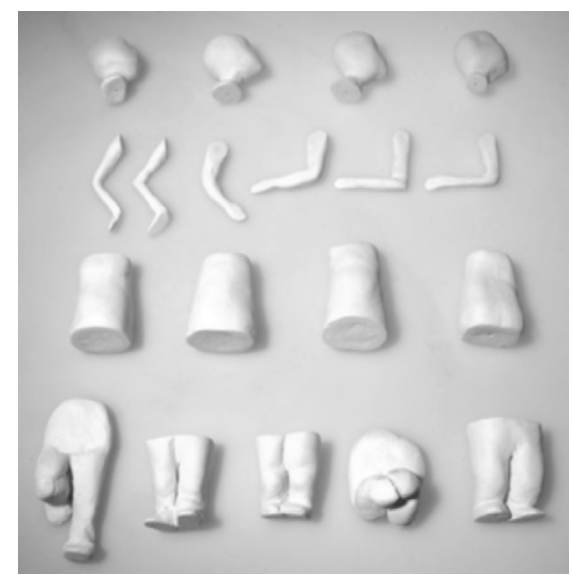

Fig. 18. Piezas del segundo prototipo. 

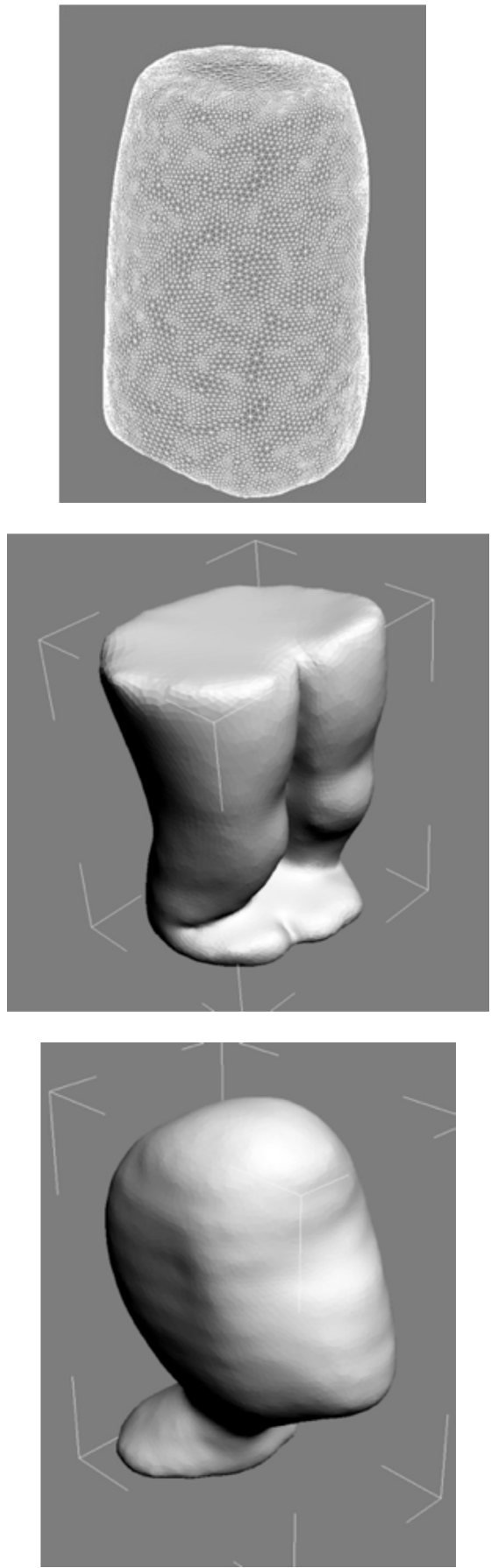
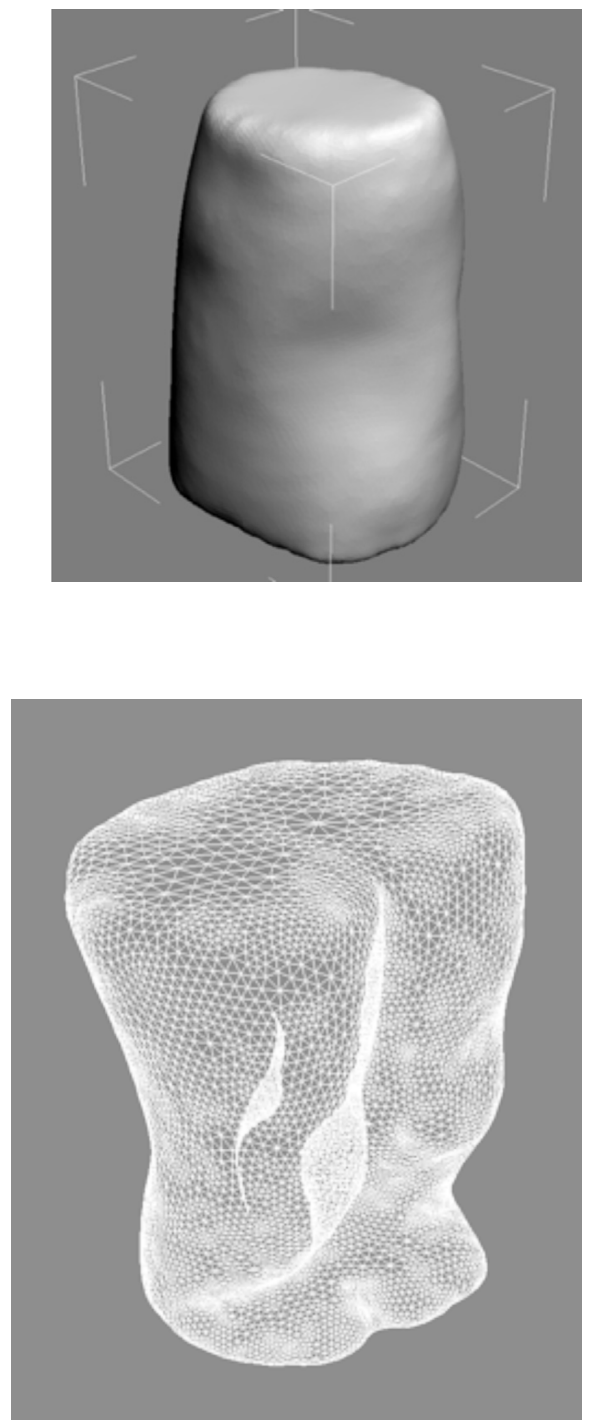

Fig. 19, 20, 21, 22, 23. Fotogramas del modelado en 3D. 


\section{Conclusiones}

En el proceso de creación de este prototipo se han tenido en cuenta:

- Los talleres realizados con anterioridad en la Unidad de Psiquiatría de adolescentes (Hospital Gregorio Marañón), con el fin de seleccionar las propuestas o actividades artísticas más adecuadas para los adolescentes hospitalizados.

- Estudio y selección de los posibles materiales para la realización de estas actividades, así como su adaptación para su uso hospitalario.

- Resultados plásticos y artísticos de los propios adolescente hospitalizados.

- Propuestas y diseños de investigadores del proyecto curarte I+D.

Especificaciones técnicas para el diseño y la fabricación del prototipo final: para la digitalización de las figuras hechas en plastilina se usó un escáner 3D portátil Kónica Minolta VIVID 910 fijo. Las piezas fueron escaneadas por partes. Para la unión de las distintas mallas que configuraban las piezas se utilizó un software como el Rapidform 2006. Además, este software también se usó para corregir fallos en las mallas, así como para optimizar las mismas.

También se usó el programa de animación 3D Studio Max 2011 y el software de modelado orgánico ZBRUSH 3.1. Una vez digitalizadas, retocadas y optimizadas las piezas se pasó a realizar el modelado de las mismas. Para ello se utilizó una modeladora Roland modelo MODELA 3D PLOTTER MDX-15.

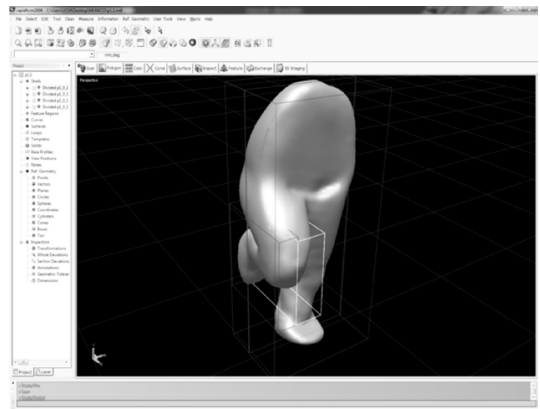

Fig. 24. 3D Studio Max 2011.

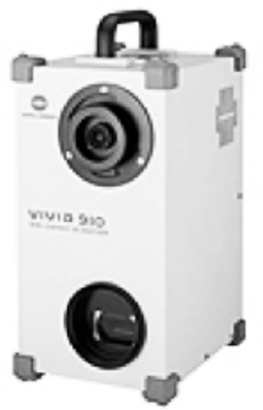

Fig. 26. Escáner 3D portátil Kónica Minolta VIVID 910.

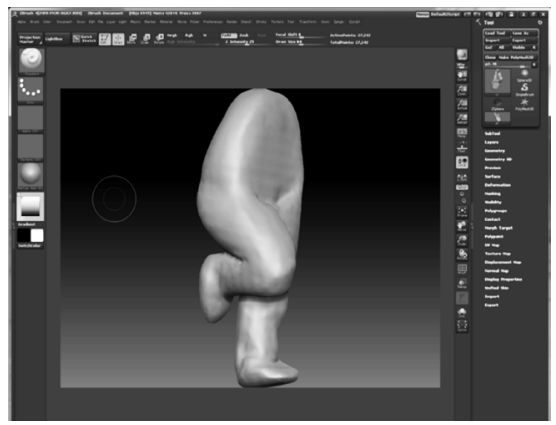

Fig. 25 ZBRUSH 3.1.

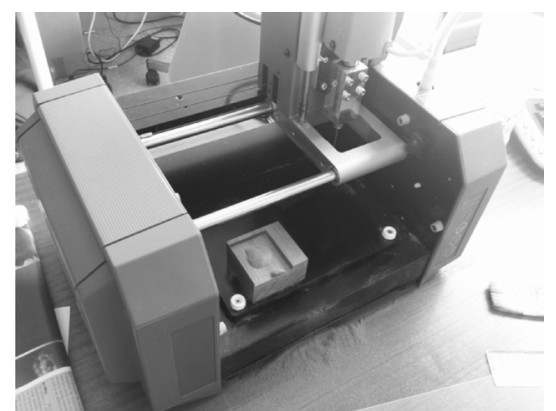

Fig. 27. MODELA 3D PLOTTER MDX-15. 


\section{Referencias}

Megías, C. 2008: Fotografía digital como herramienta para el desarrollo de actividades creativas con adolescentes hospitalizados. (Diploma de Estudios Avanzados no publicada) Universidad Complutense de Madrid.

Pascale, P. y Avila, N. 2007: Una experiencia de creatividad con adolescentes hospitalizados: unidad de psiquiatría de adolescentes del Gregorio Marañón. Arte, individuo y sociedad, 19, 207-246.

Ullán, A. González, R. y Manzanera, P. 2009: El cuidado de los adolescentes en los hospitales españoles: los pacientes invisibles. Revista de Calidad Asistencial. 2010. doi:10.1016/j.cali.2009.12.006. 